\title{
Characterization of thyroid cancer driven by known and novel ALK fusions
}

\author{
Federica Panebianco1,*, Alyaksandr V Nikitski1,*, Marina N Nikiforova1, Cihan Kaya1, Linwah Yip², \\ Vincenzo Condello ${ }^{1}$, Abigail I Wald ${ }^{1}$, Yuri E Nikiforov ${ }^{1}$ and Simion I Chiosea ${ }^{1}$
}

1Department of Pathology, University of Pittsburgh Medical Center, Pittsburgh, Pennsylvania, USA

2Division of Endocrine Surgery, University of Pittsburgh Medical Center, Pittsburgh, Pennsylvania, USA

Correspondence should be addressed to S I Chiosea: chioseasi@upmc.edu

*(F Panebianco and A V Nikitski contributed equally to this work)

\begin{abstract}
ALK fusions are found in various tumors, including thyroid cancer, and serve as a diagnostic marker and therapeutic target. Spectrum and outcomes of $A L K$ fusions found in thyroid nodules and cancer are not fully characterized. We report a series of $44 \mathrm{ALK}$ translocated thyroid neoplasms, including 31 identified preoperatively in thyroid fineneedle aspirates (FNA). The average patients' age was 43 years (range, 8-76 years); only one with radiation history. All 19 resected thyroid nodules with $A L K$ fusion identified preoperatively were malignant. Among nodules with known surgical pathology $(n=32)$, $84 \%$ were papillary thyroid carcinomas (PTCs) and $16 \%$ poorly differentiated thyroid carcinomas (PDTCS). PTCs showed infiltrative growth with follicular architecture seen exclusively (30\%) or in combination with papillary and/or solid growth (37\%). Tumor multifocality was seen in 10 (31\%) PTC cases. Most PDTC had a well-differentiated PTC component. Lymph node metastases were identified in 10/18 (56\%) patients with neck dissection. The most common ALK fusion partners were STRN $(\mathrm{n}=22)$ and EML4 $(\mathrm{n}=17)$. In five cases, novel ALK fusion partners were discovered. All five PDTCs carried STRN-ALK fusion. On follow-up, ten patients were free of disease at 2-108 months, whereas two patients with PDTC died of disease. In summary, ALK fusion-positive thyroid carcinomas are typically infiltrative PTC with common follicular growth, which may show tumor dedifferentiation associated with increased mortality. Compared to EML4-ALK, STRN-ALK may be more common in PDTC, and $\sim 10 \%$ of $A L K$ fusions occur to rare gene partners. When $A L K$ fusion is detected preoperatively in FNA samples, malignancy should be expected.
\end{abstract} Key Words

\section{Introduction}

Thyroid cancer is one of the most quickly increasing in incidence cancer types (Siegel et al. 2019), with papillary thyroid carcinoma (PTC) being the predominant morphologic type. The diagnosis and management of thyroid cancer depends on clinical stage, morphologic type, and molecular profile (Fagin \& Wells 2016,
- ALK

- FNA

- papillary thyroid carcinoma

- NIFTP 
protein-like 4 (EML4), have been reported in 1-3\% of PTCs and with a higher frequency in poorly differentiated thyroid carcinomas (PDTCs) (Cancer Genome Atlas Research Network 2014, Kelly et al. 2014, Chou et al. 2015, Landa et al. 2016, Bastos et al. 2018). Several anaplastic thyroid carcinomas carrying STRN-ALK have also been reported (Kelly et al. 2014, Perot et al. 2014, Godbert et al. 2015). The role of $S T R N-A L K$ in the progression from PTC to PDTC thyroid carcinoma has been documented (Nikitski et al. 2018). More recently, new fusion partners of $A L K$ have been identified in thyroid cancer including TFG, GTF2IRD1, and CCDC149 (McFadden et al. 2014, Landa et al. 2016, Vanden Borre et al. 2017). However, the prevalence and spectrum of specific $A L K$ fusion types and impact of $A L K$ fusion partners on tumor phenotype and outcomes remain unknown.

The standard approach to thyroid cancer includes surgery followed by radioactive iodine (RAI) for carcinomas with a higher risk of recurrence. In the management of thyroid nodules and cancers, $A L K$ fusions represent both a diagnostic marker and a potential therapeutic target. The role of ALK as a therapeutic target is being highlighted by a number of case reports of patients with $A L K$-positive thyroid cancer, including cases of metastatic and RAI-resistant cancer treated with Crizotinib (Demeure et al. 2014, Godbert et al. 2015, Ji et al. 2015, Van Der Tuin et al. 2019).

We have previously shown that thyroid fine-needle aspirates (FNA) are a reliable source for the detection of $A L K$ fusions, assisting in the diagnosis and management of cytologically indeterminate thyroid nodules (Nikiforova et al. 2018). In prior studies, $A L K$-translocated thyroid carcinomas were identified by testing resected and histologically diagnosed thyroid carcinomas. The frequency of $A L K$-translocated thyroid neoplasms prospectively identified by molecular testing of thyroid FNAs is not known and the cytological and histopathological characteristics of these nodules have not been reported.

A significant proportion of $A L K$-translocated thyroid carcinomas were reported as follicular variant of PTC prior to the reclassification of the encapsulated forms of such tumors as non-invasive follicular thyroid neoplasm with papillary-like nuclear features (NIFTP) (Nikiforov et al. 2016). Therefore, whether or not $A L K$ fusions may occur in NIFTP remains unknown.

In this study, we report the detailed analysis of a large series of $A L K$-translocated thyroid tumors, many of which were identified preoperatively by testing thyroid FNA samples, with particular focus on (i) histopathologic characteristics of tumors, including features of NIFTP, (ii) outcomes when detected preoperatively, and (iii) spectrum of $A L K$ fusion partners and discovery of novel types of $A L K$ fusions.

\section{Methods}

\section{Patient selection and study samples}

Surgically resected formalin-fixed paraffin-embedded (FFPE) tissue or thyroid FNA samples were used to identify ALK fusions (Tables 1 and 2, and Supplementary Table 1 , see section on supplementary data given at the end of this article). Thirteen patients with $A L K$-translocated thyroid carcinomas were identified by testing FFPE tissue from surgical resections (Table 1). Surgically resected cases were tested on clinical request, as part of patient's management. Thirty-one additional patients were identified by testing thyroid FNA samples, 19 of which underwent thyroid surgery (Table 2); 12 of these patients did not have follow-up data available, and it is unknown whether thyroid surgery was performed (Supplementary Table 1). Snap-frozen tissue and FFPE tissue were collected at the Department of Pathology, University of Pittsburgh Medical Center (UPMC) following approval by the University of Pittsburgh Institutional Review Board (IRB 991206). This project used the University of Pittsburgh Medical Center, Hillman Cancer Center and Tissue and Research Pathology/Pittsburgh Biospecimen Core shared resource which is supported in part by award P30CA047904. Study was done in accordance with US Federal Policy for the Protection of Human Subjects.

\section{Pathologic examination}

Two authors (S I C and Y E N) reviewed the pathology slides. In addition to standard TNM staging parameters (American Joint Committee on Cancer, $8^{\text {th }}$ edition), growth pattern, histologic variant, presence of infiltrative growth, and criteria for NIFTP were considered (Nikiforov et al. 2016, 2018). Follicular variant was defined as having no appreciable $(<1 \%)$ papillary component. PDTCs were diagnosed following Turin criteria (Volante et al. 2007). For ALK immunohistochemical analysis, $4 \mu \mathrm{m}$ FFPE sections were hybridized with primary monoclonal antibodies (Anaplastic Lymphoma Kinase, D5F3, Cell Signaling Technology, Inc) following the manufacturer's protocol.

\section{Detection of $A L K$ fusions}

Testing of thyroid FNAs and FFPE-resected thyroid carcinomas as part of clinical care was performed using 


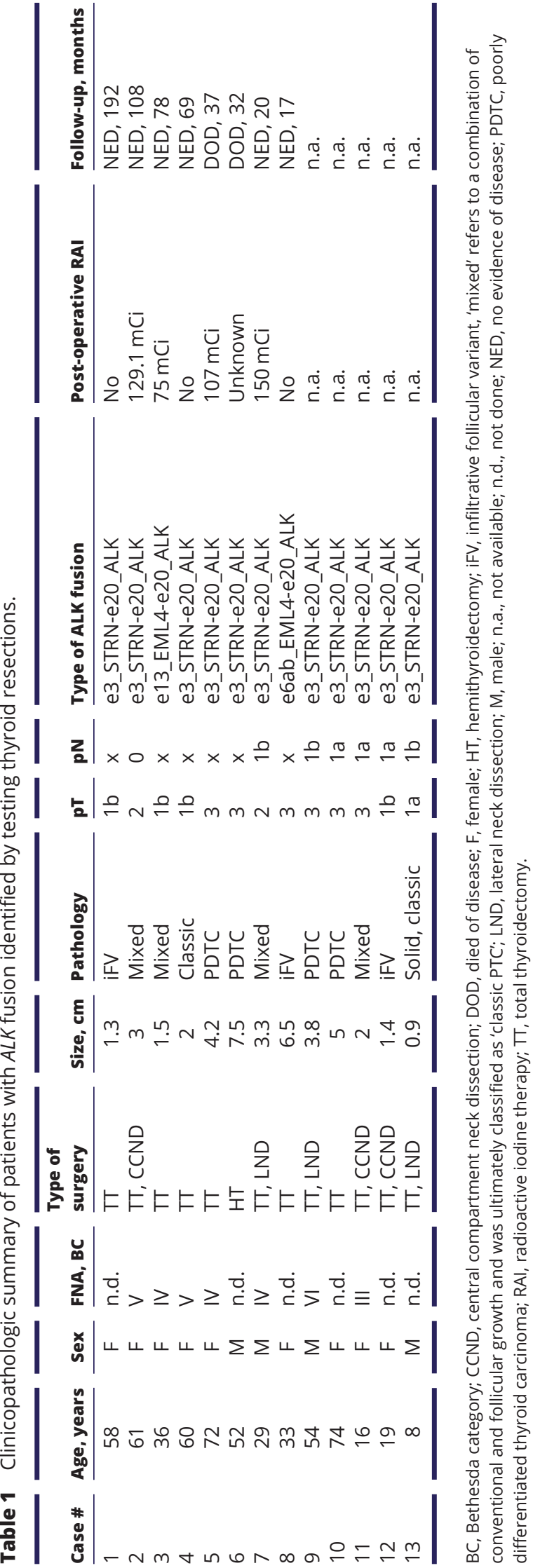

https://erc.bioscientifica.com https://doi.org/10.1530/ERC-19-0325 targeted next-generation sequencing-based ThyroSeq ${ }^{\circledR}$ v3 assay as previously described (Nikiforova et al. 2018, Steward et al. 2019). The assay uses RNA to test for all previously reported types of $A L K$ fusions and also detects the expression levels of $A L K$ tyrosine kinase (TK) domain and of extracellular (EC) domain. Samples with disproportional overexpression of the TK over EC domain of $A L K$ and negative for known types of $A L K$ fusion underwent whole transcriptome analysis (RNA-Seq).

\section{RNA-Seq and data analysis}

Total RNA was used to prepare the library for RNA exome sequencing with Illumina TruSeqTM RNA Exome Sample Preparation kit v1 (Illumina, Inc). The prepared libraries were assessed using an Agilent 2200 TapeStation, and then denatured with sodium hydroxide and loaded on Illumina HiSeq2500. Cluster generation and paired-end sequencing were performed using HiSeq Paired-End Rapid Cluster kit v2 and HiSeq Rapid SBS kit v2 (Illumina, Inc). The filtered high-quality reads were aligned to the human genome (hg19-GRCh37) using TopHat aligner (Trapnell et al. 2009) and number of reads mapped to each gene was calculated using RSeM (Li \& Dewey 2011) and featureCounts (Liao et al. 2014). Gene fusions were detected using Q-score (Li et al. 2008), Chimerascan with custom filtering algorithm (Iyer et al. 2011), Atlas (Huret et al. 2013), CIS (RTCGD) (Akagi et al. 2004), and CHCG (Futreal et al. 2004) databases. The junctions and the individual exon expression levels were used to visualize the fusion point.

\section{RT-PCR and Sanger sequencing}

RNA was subjected to DNase treatment using the Invitrogen DNA-free ${ }^{\mathrm{TM}}$ kit (Thermo Fisher Scientific). The RNA from frozen tissues was reverse transcribed by Applied Biosystems High-Capacity cDNA Reverse Transcription Kit (Thermo Fisher Scientific). The RNA from FFPE tissues and FNA was reverse transcribed by Invitrogen SuperScript IV VILO Master Mix (Thermo Fisher Scientific). RT-PCR was conducted using HotStarTaq DNA Polymerase (Qiagen), and primers listed in Supplementary Table 2. The RT-PCR products were sequenced in both directions using the Applied Biosystems BigDye Terminator Kit and an ABI 3130xl DNA Sequencer (Thermo Fisher Scientific).

\section{Western blot analysis}

Total protein was isolated from frozen tissue homogenized in RIPA buffer (Boston BioProducts, Ashland, MA, USA) 


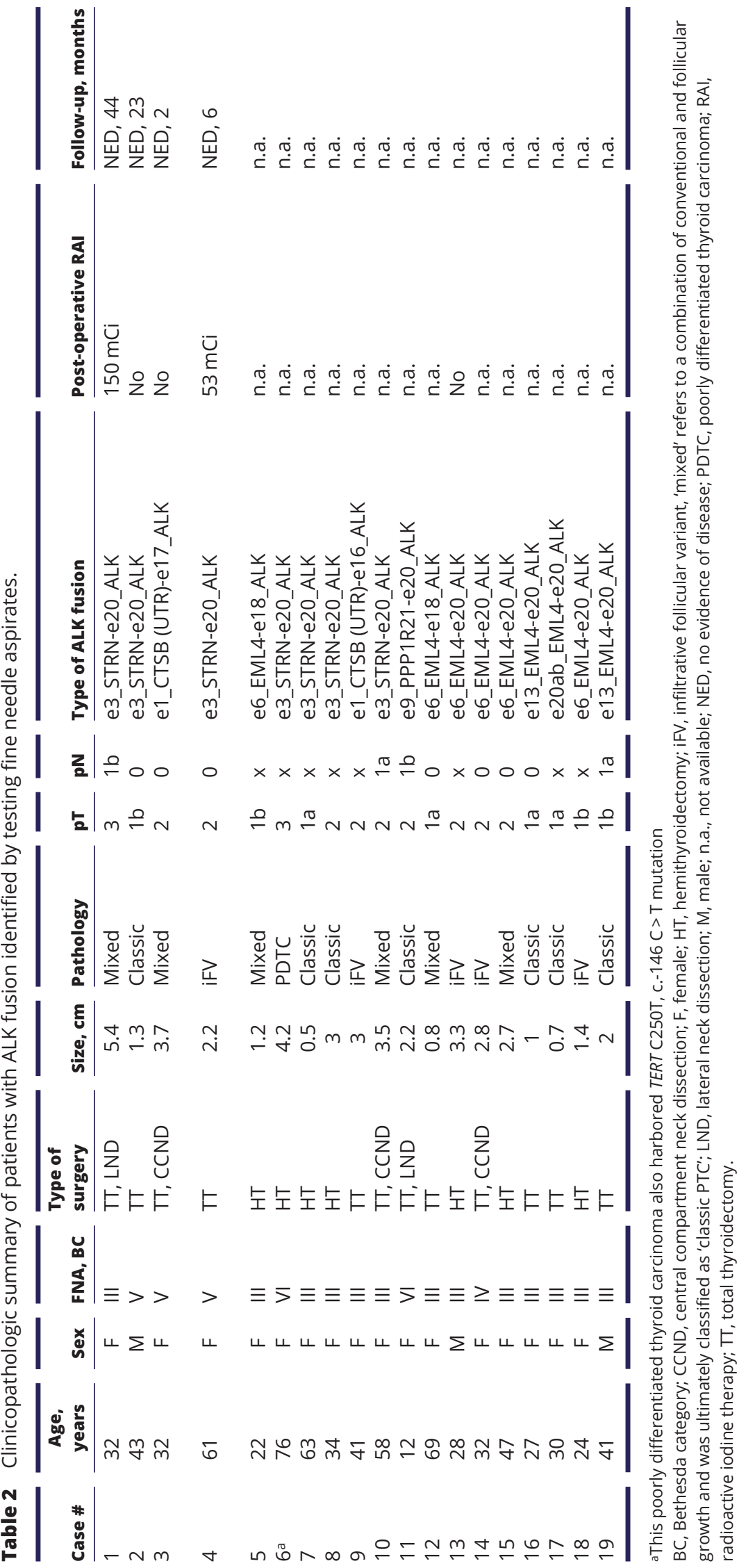


using OMNI-GLH (OMNI International, Kennesaw, GA, USA); $40 \mu \mathrm{g}$ of total protein was resolved by SDS-PAGE and transferred to nitrocellulose membrane (Bio-Rad Laboratories). The membranes were incubated overnight at $4^{\circ} \mathrm{C}$ with ALK (D5F3, 1:2000, Cell Signaling) or $\beta$-actin (1:1000, Cell Signaling) antibodies, followed by anti-rabbit (1:10000, Promega) HRP-conjugated secondary antibody and signals were detected by ECL (GE Healthcare).

\section{Results}

\section{Clinical and morphologic characteristics}

Forty-four patients with $A L K$-translocated thyroid neoplasms were identified in either surgically removed tumors $(n=13)$ or thyroid FNA samples $(n=31)$. The overall average age of patients was 43.4 years (range, 8-76 years), including two pediatric patients, an 8-yearold boy and a 12-year-old girl. Overall, female patients were predominant, $36 / 44(82 \%)$. The average size of $A L K$-translocated thyroid nodules was $2.8 \mathrm{~cm}$ (range, $0.7-7.5 \mathrm{~cm}$ ). Thyroid FNA was performed on 38 patients and diagnosed in cytology as Bethesda Category (BC) III $(25 / 38,66 \%)$, BC IV $(4 / 38,10 \%)$, BC V $(6 / 38,16 \%)$, and BC VI $(3 / 38,8 \%)$. Additional clinicopathologic and molecular parameters of 44 patients with $A L K$-translocated thyroid neoplasms are summarized in Tables 1 and 2, and Supplementary Table 1. Only one patient had a remote history of therapeutic exposure to RAI, reportedly for multinodular goiter (case \#12, Table 2).

Surgical pathology data were available for 32 patients (Tables 1 and 2). The most common procedure was a total thyroidectomy $(24 / 32,75 \%)$. The most common histologic diagnosis was that of well-differentiated PTC $(27 / 32,84 \%)$, followed by five cases of PDTC $(5 / 32,16 \%)$. The PTC had a predominantly follicular growth pattern with areas of papillary and/or solid growth in 10 cases $(10 / 27,37 \%)$ or without papillary growth meeting the criteria for infiltrative FV PTC $(8 / 27,30 \%)$ (Fig. 1). The remaining 33\% (9/27) of PTC had predominantly classic papillary growth pattern with no significant follicular component. Overall, although the proportion of conventional papillary component varied, 19/27 (70\%) of PTCs were categorized as classic PTCs due to the presence of well-formed papillary structures. Papillae were typically tightly packed and covered by cells with well-developed nuclear features of PTC. The neoplastic follicles were typically irregularly shaped and contained a significant amount of colloid. Nuclear features of PTC were overall less prominent in the areas of follicular growth, with nuclear pseudoinclusions only rarely found. Multifocal PTC was noted in ten cases (10/32, 31\%).

PDTC carrying ALK fusions had predominantly solid growth with a minor component of trabecular and insular architecture in some cases (Fig. 2A and B). Necrosis was identifiable in all cases. The nuclei of PDTC cells were either of smaller size with dark uniformly dispersed chromatin (three tumors, Fig. 2C) or larger size with vesicular chromatin (two tumors, Fig. 2D). Nuclear features of PTC were lost in these areas. Four out of five PDTC tumors also contained areas of well-differentiated PTC, either follicular variant or classic type. One PDTC showed an additional genetic alteration, TERT C250T mutation (Case \#6, Table 2), whereas all other tumors had an $A L K$ fusion as the only driver mutation identified.
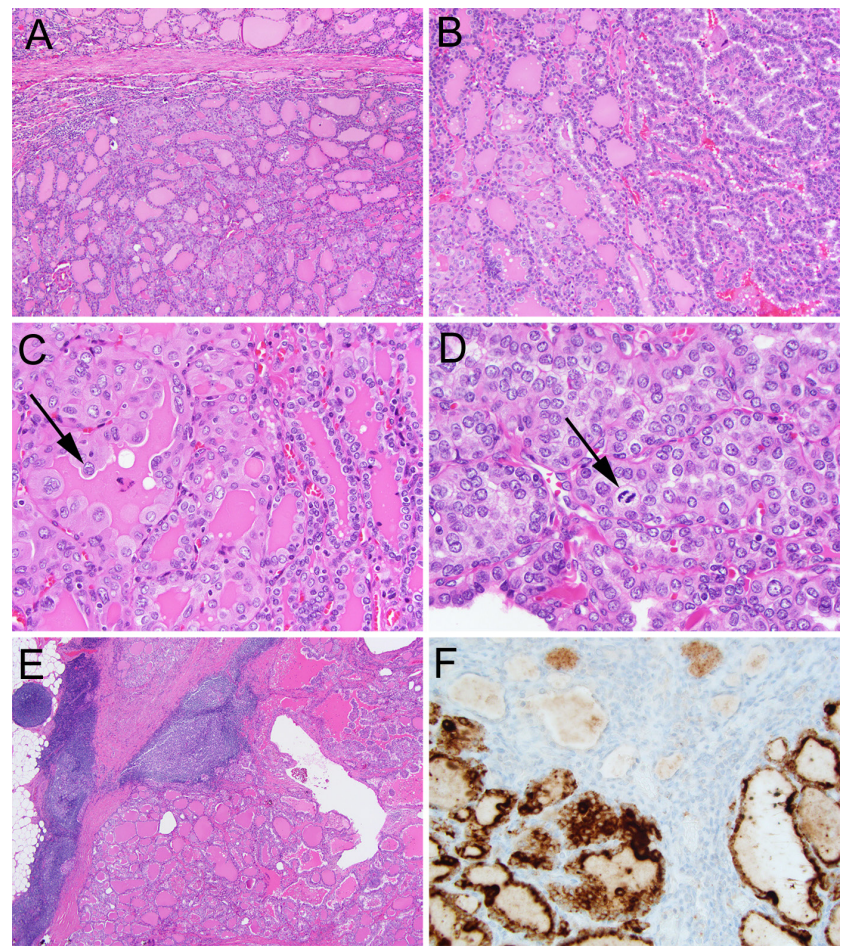

\section{Figure 1}

Histopathologic features of representative cases of papillary thyroid carcinoma with ALK fusions. (A) Papillary thyroid carcinoma with mixed conventional and follicular growth; component of follicular growth was well circumscribed and thinly encapsulated. H\&E, 100x. (B) Interface between follicular (left) and tightly packed papillary (right) components. H\&E, 200×. (C) Well-developed nuclear features of papillary thyroid carcinoma (including nuclear pseudo-inclusions, arrow) in the conventional component. H\&E, 400×. (D) A minor (<10\%) component of solid growth with mitosis (arrow; 1 in 10 high power (200x) fields). H\&E, $600 \times$. (E) Lateral neck lymph node with metastatic papillary thyroid carcinoma, mixed follicular and conventional. H\&E, 40×. (F) ALK immunohistochemistry, strong diffuse cytoplasmic staining of tumor cells and weak colloid-only background staining in the adjacent normal thyroid, $400 \times$. c) 2019 Society for Endocrinology Published by Bioscientifica Ltd. Printed in Great Britain 


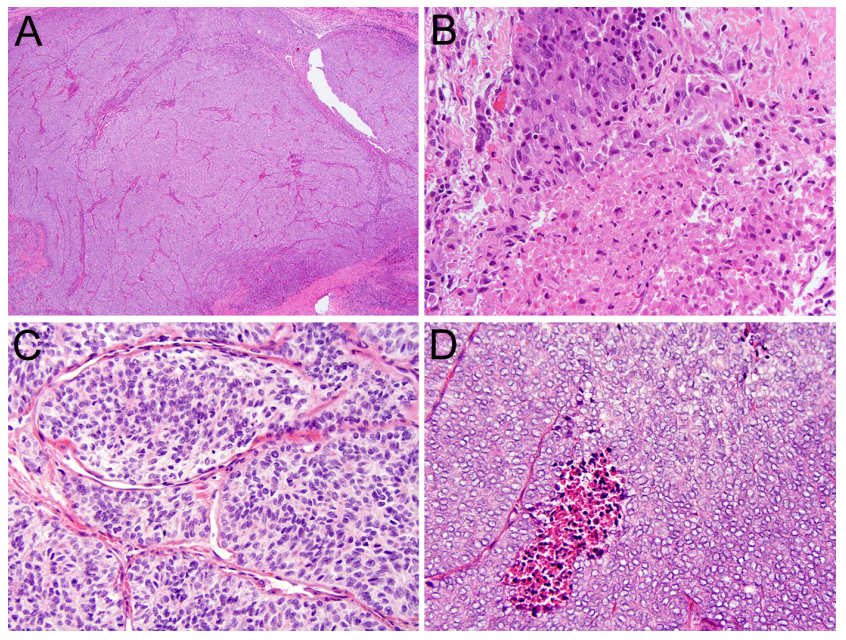

Figure 2

Histopathologic features of poorly differentiated thyroid carcinomas with ALK fusions. (A) Solid and trabecular growth (H\&E, 40×). (B) Areas of tumor necrosis (H\&E, 400×). (C) This tumor shows smaller, dark nuclei and significant amount of cytoplasm (H\&E, 200×). (D) This tumor has punctate necrosis, larger nuclei with vesicular chromatin, smooth nuclear contours without grooves or pseudoinclusions, and small amount of cytoplasm (H\&E, 200×).

Extrathyroidal extension was identified in six cancers $(6 / 32,19 \%)$, four of which were PDTC. There were 11 cases with pT2, 8 cases with pT3, and 8 cases with pT1b. Lymph node dissection was performed in 18 patients and resulted in pN0 $(n=8)$, pN1a $(n=5)$, and pN1b $(n=5)$. Of ten patients with lymph node metastases, two patients had PDTC.

ALK IHC was performed on 12 tumors and was positive in 11 cases $(11 / 12,92 \%)$. One case showed indeterminate ALK IHC result and the lack of staining was likely caused by suboptimal tissue preservation in a 10-year-old FFPE tissue block.

Clinical follow-up was available for 12 patients (Tables 1 and 2). Five patients received post-operative RAI therapy (dose ranging from 53 to $150 \mathrm{mCi}$ ). Ten patients were free of disease 2-108 months after thyroid surgery. Two patients with PDTC developed multiple distant metastases and died of disease 32 and 37 months after surgery.

\section{Preoperative detection in thyroid FNA samples}

Thirty-one nodules positive for $A L K$ fusions were identified by testing thyroid FNA samples. This included 15 cases with $A L K$ fusions detected prospectively by ThyroSeq testing of 11,211 consecutive thyroid FNAs with indeterminate cytologic diagnosis over an 11-month period from December 2017 to September 2018, yielding the frequency of $0.13 \%$. Overall, among all nodules with
$A L K$ fusions first detected in FNA samples, the cytological diagnosis of Bethesda Category (BC) III was established in $23(74 \%)$ cases, BC IV in $1(3 \%)$, BC V in $5(16 \%)$, and BC VI in $2(7 \%)$.

Nineteen nodules positive for $A L K$ fusions in thyroid FNA samples had a known surgical pathology outcome. All 19 were ultimately diagnosed as malignant, including 18 PTC and 1 PDTC. In all but one case, the carcinoma was diagnosed by primary case pathologists. In Case \#5 (Table 2), the $1.2 \mathrm{~cm}$ thyroid nodule initially diagnosed as NIFTP was mostly well circumscribed, but it was lobulated, had complex central fibrous septae outlining the initial primary capsule of a smaller nodule, and a minor conventional component of PTC (Fig. 3A, B and C). ALK immunohistochemistry highlighted foci of infiltration at the lesion-normal tissue interface (Fig. 3D).

Among patients with $A L K$ fusions identified by testing preoperative FNA samples (Table 2), the frequency of known lymph node metastases was $4 / 19,21 \%$.

\section{Spectrum of $A L K$ fusions and detection of novel fusion partners}

The most common fusion partners of $A L K$ were STRN (22/44, 50\%) and EML4 (17/44, 39\%). In 5/44 (11\%) cases, $A L K$ fusions involving novel partners were identified.
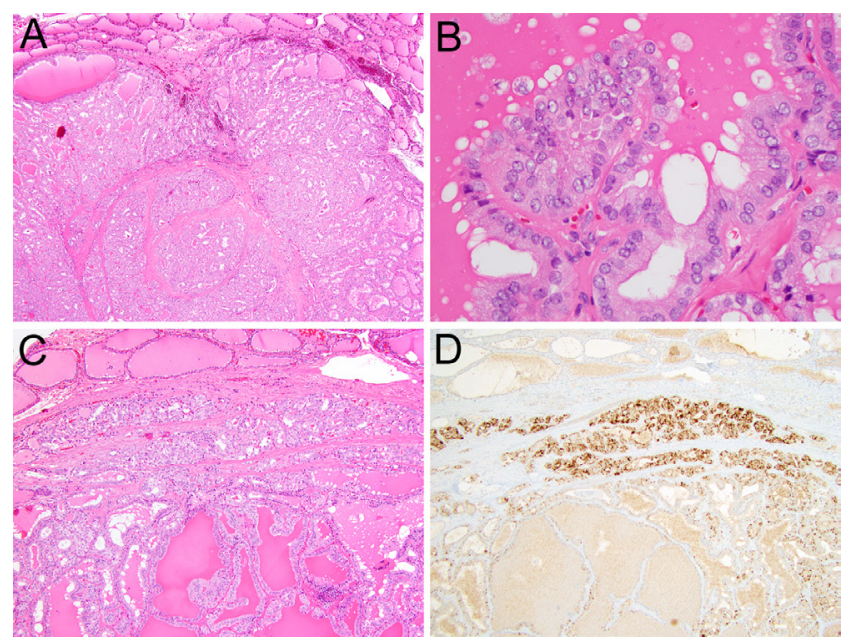

\section{Figure 3}

Histopathologic features of papillary thyroid carcinoma initially diagnosed as NIFTP (case \#5, Table 2). (A) This $1.2 \mathrm{~cm}$ thyroid mass was mostly well circumscribed and lobulated. The center of the mass showed complex fibrous septae, perhaps outlining the initial primary capsule of the smaller nodule. $H \& E, 40 \times$. (B) About $5 \%$ of the mass showed branching papillae covered by follicular cells with nuclear features of papillary thyroid carcinoma. $\mathrm{H} \& \mathrm{E}, 600 \times$. (C) Periphery of the mass with split thin capsule and permeating tumor cells. H\&E, 100×. (D) ALK immunohistochemistry highlighting the focus of infiltration shown in (C), 100×.
(C) 2019 Society for Endocrinology Published by Bioscientifica Ltd. Printed in Great Britain 
Table 3 New types of ALK rearrangements detected in thyroid cancer.

\begin{tabular}{|c|c|c|c|c|}
\hline Fusion name & Cytogenetic characteristics & $\begin{array}{l}\text { Dimerization domain of } A L K \\
\text { fusion partner }\end{array}$ & Encoding ALK exons & $\begin{array}{c}\text { I } \\
\text { Predicted protein size }\end{array}$ \\
\hline ITSN2 e29-ALK e18 & $\mathrm{t}(2 ; 2) ;(\mathrm{p} 23.3 ; \mathrm{p} 23.2)$ & Coiled-coil & e18-e29 & 1841 aа \\
\hline $\begin{array}{l}\text { PPP1R21 e9/i9-ALK } \\
\text { e20 }\end{array}$ & $\mathrm{t}(2 ; 2) ;(\mathrm{p} 16.3 ; \mathrm{p} 23.2)$ & Coiled-coil & e20-e29 & 844 aa \\
\hline$P P P 1 R 21$ e7-ALK e20 & $\mathrm{t}(2 ; 2) ;(\mathrm{p} 16.3 ; \mathrm{p} 23.2)$ & Coiled-coil & e20-e29 & 794 aа \\
\hline CTSB e1-ALK e16 & $\mathrm{t}(8 ; 2) ;(\mathrm{p} 23.1 ; \mathrm{p} 23.2)$ & Nonea & e16-e29 & 711 aаa $^{a}$ \\
\hline CTSB e1-ALK e17 & $\mathrm{t}(8 ; 2) ;(\mathrm{p} 23.1 ; \mathrm{p} 23.2)$ & None ${ }^{a}$ & e17-e29 & $671 \mathrm{aa}^{a}$ \\
\hline
\end{tabular}

aTranslation start codon in ALK exon16 or ALK exon 17; exon 1 of the partner gene untranslated

These cases initially showed a preferential overexpression of the tyrosine kinase domain of $A L K$ over the extracellular domain, suggesting the presence of $A L K$ fusion, with no known fusion types identified. On subsequent RNA-Seq analysis, these cases revealed in-frame $A L K$ fusion to novel partner genes including cathepsin B (CTSB) $(n=2)$, protein phosphatase 1 regulatory subunit 21 (PPP1R21) $(n=2)$, and intersectin 2 (ITSN2) $(n=1)$ (Table 3). Unlike $A L K$, all of these three genes were found to be expressed in normal thyroid follicular cells, driving the expression of the fused part of $A L K$ coding for the tyrosine kinase domain of the protein.

Two of these tumors revealed the fusion between exon 1 of CTSB and either exon 17 (Fig. 4) or exon 16
(Supplementary Fig. 1) of $A L K$. Interestingly, exon 1 of CTSB is part of the $5^{\prime}$-UTR and is untranslated, suggesting the presence of an alternative translation site in the chimeric genes. Indeed, alternative translation initiation sites in $A L K$ exons 16 and 17 have been reported (Gasteiger et al. 2003). In the CTSB exon 1-ALK exon 17 fusion, a putative translation start codon is located in $A L K$ exon 17 at chr2:29,450,506-29,450,504 (GRCh37/hg19). The expression of ALK protein in this tumor was confirmed by immunohistochemistry (Fig. 1F) and Western blot analysis (Fig. 4D). In CTSB exon $1-A L K$ exon 16 fusion, a putative alternative translation start codon in $A L K$ exon 16 is located at chr2:29,451,837-29,451,835 (GRCh37/hg19).
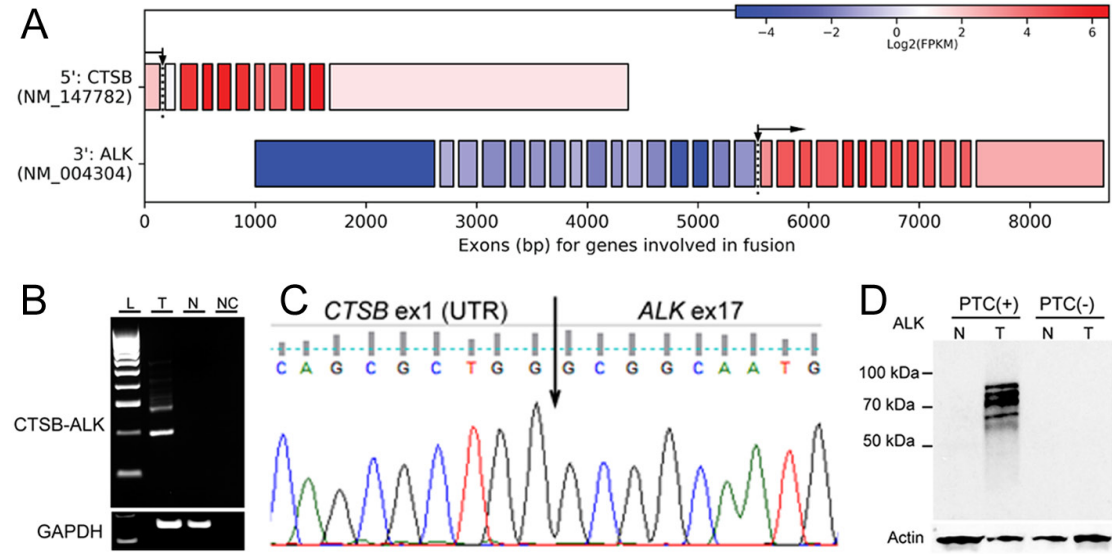

\section{CTSB ex1 (UTR)} C A G C G C T G G

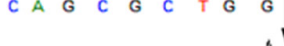
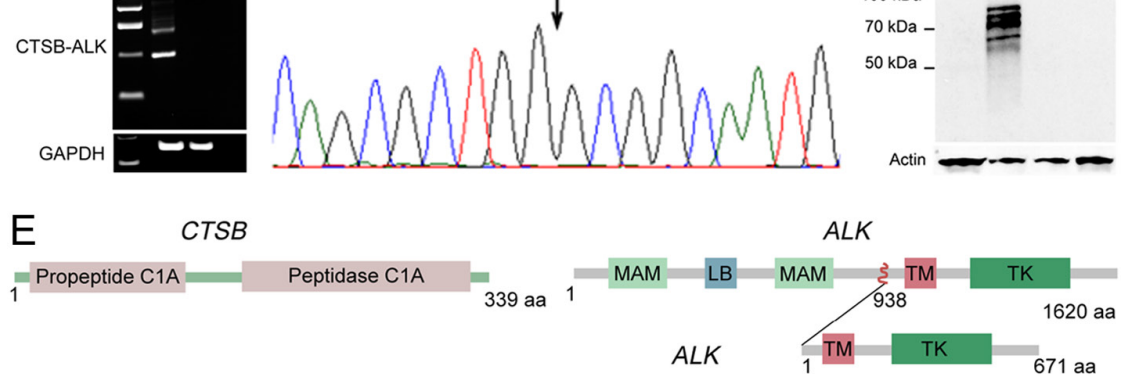

\section{Figure 4}

Identification and confirmation of CTSB (exon 1)-ALK (exon 17) fusion. (A) Analysis of mRNA expression levels of individual CTSB and ALK exons using RNA-Seq data showing overexpression of ALK exons 17-29 downstream of the fusion point. Each box represents an exon and the boxes are colored according to the logarithm of their expression levels as measured in reads per kilobase per million reads. (B) RT-PCR confirmation of CTSB-ALK fusion. L, 100-bp ladder; $\mathrm{N}$, normal tissue; $\mathrm{NC}$, negative control; $\mathrm{T}$, tumor. (C) Sanger sequencing confirmation of CTSB (exon 1)-ALK (exon 17) fusion. Ex, exon; UTR, untranslated region. (D) Western blot analysis of papillary thyroid carcinomas positive (PTC+) and negative (PTC-) for CTSB-ALK fusion and corresponding normal tissue (N). Western blot analysis using ALK antibody showed three bands around 70 to $80 \mathrm{kDa}$, suggesting the ALK protein translation from more than one start codon in ALK exon 17 or post-translational protein modifications. No ALK protein was detected in normal thyroid tissue or in thyroid tumors lacking this fusion. (E) Schematic representation of the predicted fusion protein retaining the transmembrane domain (TM) and tyrosine kinase (TK) domain of ALK. Propeptide, Peptidase C1A-propeptide; Peptidase C1A, c-terminal; MAM, merpin, A5 protein and receptor protein tyrosine $\mathrm{mu}$; LB, ligand-binding domain. 
Another two cases showed fusions between PPP1R21 either exon 7 (Supplementary Fig. 2) or exon 9 (Supplementary Fig. 3) and exon 20 of $A L K$. In the latter case, RT-PCR analysis showed the retention of a 17-nucleotide fragment of PPP1R21 intron 9 at the fusion site, leading to an in-frame mRNA transcript. Finally, a fusion between exon 29 of ITSN2 and exon 18 of ALK was found in one case (Supplementary Fig. 4).

Among 32 cases with surgical pathology data available, there were 18 tumors with STRN-ALK, 11 with EML4-ALK, and 3 with novel types of $A L K$ fusions. All five PDTC cases carried STRN-ALK $(P=0.07$, Fisher exact probability test). Among PTCs, no significant variability in the predominance of follicular, solid, or classic papillary architecture was noted between tumors with different types of $A L K$ fusions.

\section{Discussion}

In this study, we provide an in-depth characterization of the largest cohort of patients with $A L K$-translocated thyroid cancer reported to date. The average age of patients in our series was comparable to that of patients with PTCs unselected for genetic alterations: 43.4 (8-76) versus 46.8 (15-89) years, respectively (Cancer Genome Atlas Research Network 2014). The current study describes two pediatric patients, confirming previous observations of this fusion occurring in pediatric patients (Chou et al. 2015, Park et al. 2015, Vanden Borre et al. 2017, Arndt et al. 2018). The overall predilection for female patients appears to be more prominent in $A L K$-translocated group: 4.5:1 versus 2.7:1 among PTC patients unselected for $A L K$ fusions (Cancer Genome Atlas Research Network 2014). The age and sex distribution of $A L K$-translocated thyroid carcinomas in this study are comparable to those previously reported (Table 4).

ALK-translocated thyroid carcinomas can occur both in patients with and without a history of radiation exposure. However, the prevalence of $A L K$ fusions appears to be higher, up to 7.6-9\% (Hamatani et al. 2012, Arndt et al. 2018, Efanov et al. 2018), in PTCs from radiationexposed patients. An additional approach to increasing the chance of identifying $A L K$ fusions is to exclude thyroid carcinomas with other, more common driver mutations such as BRAF, RAS, and RET/PTC. Of $44 A L K$-translocated thyroid carcinomas presented here, only one PDTC showed an additional genetic alteration - TERT promoter mutation. Other studies identified an RAI-refractory conventional PTC with EML4-ALK fusion and TERT mutation (Van Der Tuin et al. 2019), STRN/ALK-positive PDTC with TERT mutation, and an EML4/ALK-positive PDTC with ATM mutation (Landa et al. 2016). Wholegenome sequencing of an RAI-resistant and recurrent PTC with EML4-ALK fusion revealed co-existing alterations in 55 genes, many of which are likely passenger mutations (Demeure et al. 2014).

Since 2012, about 60 patients with $A L K$-translocated thyroid cancer have been reported in different studies, ranging from papillary thyroid microcarcinomas to anaplastic thyroid carcinomas, with a significant number of those diagnosed as a follicular variant of PTC. Cases of PTC presented in this study and in the literature (Table 4) were evaluated with attention to identifying the most characteristic histology that could help to trigger testing for $A L K$ fusions and exploring whether the presence of $A L K$ fusion is compatible with the diagnosis of NIFTP.

Morphologically, while not pathognomonic, ALKtranslocated PTCs appear to be characterized either by a purely follicular architecture with infiltrative growth or predominance of follicular growth with islands of tightly packed papillae or classic morphology. Our analysis suggests that tumors with pure classic papillary growth pattern and absence of an appreciable follicular component are less likely to carry $A L K$ fusions. However, we acknowledge that $A L K$ fusions have been reported in tumors with other morphologies, such as diffuse-sclerosing variant of PTC (Table 4). Overall, younger to middle-aged females with infiltrative thyroid cancer showing follicular architecture and negative for $B R A F, R A S$, and other common genetic alterations are the likeliest to harbor an $A L K$ fusion.

With the growing role of $A L K$ as a diagnostic FNA marker, it was important to establish whether $A L K$ fusion can be seen in benign thyroid nodules or NIFTP (Nikiforov et al. 2016, 2018). To date, 156 follicular adenomas were shown to be negative for $A L K$ fusions (Perot et al. 2014, Park et al. 2015, Bastos et al. 2018, Nikiforova et al. 2018). Here we show that only one of $19 A L K$-translocated neoplasms (with $A L K$ fusion first identified in FNA) mimicked NIFTP. This is consistent with the data in the literature. Indeed, out of about 28 PTCs described with sufficient morphologic details (i.e., with comments on variant morphology and invasion), there were no cases of non-invasive follicular variant of PTC (Table 4), rendering the possibility of an $A L K$-positive NIFTP unlikely.

When follicular growth is predominant and infiltrative growth is subtle, ALK IHC represents a practical tool that helps to asses for invasion more objectively, especially if $A L K$ fusion was already identified by molecular testing of preoperative FNA. In this study, ALK IHC was 
Table 4 Summary of ALK-positive thyroid cancers from prior studies with basic clinicopathologic information.

\begin{tabular}{|c|c|c|c|c|c|c|}
\hline $\begin{array}{l}\text { ALK '+'/total, n (\%), } \\
\text { histologic type }\end{array}$ & Female/male & $\begin{array}{l}\text { Age, average } \\
\text { (range), years }\end{array}$ & $\begin{array}{l}\text { Morphologic variants and } \\
\text { features }\end{array}$ & Recurrence? & $\begin{array}{l}\text { Fusion } \\
\text { partner }\end{array}$ & Reference \\
\hline $11 / 498,2.2 \%$, PTC & $11: 0$ & $38(13-68)$ & $\begin{array}{l}\text { Diffuse sclerosing, } n=3 \text {; } \\
\text { iFV, } n=6 \mathrm{~g}\end{array}$ & No & $E M L 4, n=8$ & Chou et al. 2015 \\
\hline 2/129,1.5\%, FVPTC & n.a. & n.a. & PTC, $n=2$ & No $(n=1)$ & $E M L 4, T F G$ & $\begin{array}{l}\text { McFadden et al. } \\
2014\end{array}$ \\
\hline $\begin{array}{l}\text { 4/392, } 1 \% \text {, thyroid } \\
\text { carcinomas }\end{array}$ & $3: 1$ & $37(13-50)$ & $\begin{array}{l}\text { Classic, } n=2 ; \text { solid, } \\
\quad n=1 ; \mathrm{FV}(\mathrm{ETE}), n=1 ;\end{array}$ & No & STRN, $n=2$ & Park et al. 2015 \\
\hline 10/116, 8.6\%, РTC & $8: 2$ & $42(34-47)$ & $\begin{array}{l}\text { iFV, } n=4 ; \text { classic, } n=2 ; \\
\text { FV PTC, NOS, } n=4\end{array}$ & Yes, $1 / 8$ & $\begin{array}{l}\text { EML4, } n=6 \\
\text { STRN, } n=4\end{array}$ & Bastos et al. 2018 \\
\hline 1/15, PTC & $0: 1$ & 31 & Classic PTC, $n=1$ & No & $E M L 4$ & Cipriani et al. 2017 \\
\hline 1 PTCa & $0: 1$ & 62 & TCV PTC & Yes, DM & EML4 & $\begin{array}{l}\text { Demeure et al. } \\
2014\end{array}$ \\
\hline 1/12, РTCb & $0: 1$ & 27 & Classic PTC & No & $E M L 4$ & Pfeifer et al. 2019 \\
\hline 1/59, РТС & $0: 1$ & 60 & Classic PTC & AWD, 5 years & EML4 & $\begin{array}{l}\text { van der Tuin et al. } \\
2019\end{array}$ \\
\hline 3/303, 1\%, РTC & $3: 0$ & $\begin{array}{c}10 \\
(7-15)\end{array}$ & $\begin{array}{l}\text { PTC, } \mathrm{pN}+, n=1 ; \\
\mathrm{PTC}, \mathrm{NOS}, n=2\end{array}$ & n.a. & $\begin{array}{l}\text { EML4, STRN, } \\
\text { GTF2IRD1 }\end{array}$ & $\begin{array}{l}\text { Vanden Borre } \\
\text { et al. } 2017\end{array}$ \\
\hline $\begin{array}{l}\text { 3/75, thyroid } \\
\text { carcinomas }\end{array}$ & $1: 0^{e}$ & 71 & $\begin{array}{l}\text { Classic PTC, } n=2 ; \\
\text { ATC, } n=1\end{array}$ & AWDe & STRN & $\begin{array}{l}\text { Perot et al. 2014, } \\
\text { Godbert et al. } \\
2015\end{array}$ \\
\hline $\begin{array}{l}\text { 3/84,3.5\% PDTC; } \\
\text { 0/33 ATC }\end{array}$ & $1: 2$ & $(30-89)^{f}$ & PDTC, $n=3$ & Died, $n=2$ & $\begin{array}{l}\text { STRN, EML4, } \\
\text { CCDC149 }\end{array}$ & Landa et al. 2016 \\
\hline $7 / 77$ (9\%), PTCd & $5: 2$ & $23(16-34)$ & $\begin{array}{l}\text { FV PTC, } n=1 ; \text { PTC NOS, } \\
n=6\end{array}$ & n.a. & $E M L 4, n=2$ & Arndt et al. 2018 \\
\hline
\end{tabular}

aStable disease after 6 months of Crizotinib treatment.

bThyroid carcinomas negative for common mutations (e.g., BRAF, RAS).

cRAl-refractory thyroid carcinomas.

dPTC in radiation exposed patients.

eThe sex of two patients was not reported. Response after 6 months of Crizotinib therapy.

${ }^{\mathrm{f}}$ Age of individual patients was not reported.

gThere were also mixed PTC $(n=2)$, tall cell variant of PTC $(n=1)$, oncocytic PTC $(n=1)$, Warthin-like PTC $(n=1)$. Only EML4, as ALK fusion partner, was specifically tested for.

ATC, anaplastic thyroid carcinoma; AWD, alive with disease; DM, distant metastasis; ETE, extrathyroidal extension; FVPTC, follicular variant of PTC; iFV, infiltrative follicular variant; n.a., not available; NOS, not otherwise specified; PDTC, poorly differentiated thyroid carcinoma; PTC, papillary thyroid carcinoma; RAI, radioactive iodine; TCV, tall cell variant.

indeterminate in 1 of 12 cases. In the literature, there are at least two cases with known $A L K$ fusion (identified by FISH or other methods) and negative ALK IHC (Perot et al. 2014, Jeon et al. 2019).

Sixteen percent of $A L K$-translocated tumors in this study were poorly differentiated, fully meeting the Turin diagnostic criteria for PDTC (Volante et al. 2007). Interestingly, the nuclei of cells in these tumors showed two different types of morphology, correlating with the observation in the animal model of STRN-ALK-driven PDTC (Nikitski et al. 2019). Most PDTC had a welldifferentiated PTC component, suggesting that the tumors initially developed as PTC before undergoing dedifferentiation.

Previously reported cases of $A L K$-translocated thyroid carcinomas were typically identified using surgically removed tumors. In this study, we explored the frequency of $A L K$ fusions in a large consecutive series of thyroid FNA samples with predominantly indeterminate FNA cytology.
We observed that a small but distinct proportion of these aspirates were found to be positive for $A L K$ fusions, and all of those nodules were cancers. Many of these FNAs were diagnosed as Bethesda III by cytology, which is likely due to the presence of abundant colloid and only a moderate degree of expression of nuclear features of PTC in many of these tumors. In another study of ALK-positive tumors, the pre-operative cytology of such nodules was reported in four cases and included Bethesda $\mathrm{V}$ in three and Bethesda III in one case (Park et al. 2015).

Two most common fusion partners of $A L K$ were STRN and EML4 in this study and in the literature (Table 4). While we did not identify previously reported $A L K$ fusion partners such as TFG, GTF2IRD1, or CCDC149, we identified fusions with ITSN2, CTSB, and PPP1R21 genes. Of those, ITSN2-ALK and CTSB-ALK fusions have not been previously described. The ITSN2 gene encodes Intersectin 2, a member of multidomain adaptor/scaffold proteins that assemble multimeric complexes implicated in https://erc.bioscientifica.com https://doi.org/10.1530/ERC-19-0325 (c) 2019 Society for Endocrinology Published by Bioscientifica Ltd. Printed in Great Britain 
clathrin- and caveolin-mediated endocytosis and rearrangements of the actin cytoskeleton (Predescu et al. 2003, Tsyba et al. 2011). PPP1R21-ALK fusion was previously reported in colorectal carcinoma (Yakirevich et al. 2016) and was not known to occur in thyroid cancer. PPP1R21 is essential for endosome functions (Rehman et al. 2019). In $A L K$ fusions discovered prior to this report, such as STRN-ALK or EML4-ALK, ALK kinase was known to be activated via a ligand-independent dimerization of the chimeric protein mediated by the coiled-coil (CC) domain of the fusion partner with constitutive phosphorylation on Tyr1278 of ALK (Kelly et al. 2014, Holla et al. 2017). Activation through CC domain dimerization is the likely mechanism of ALK activation in PPP1R21-ALK and ITSN2-ALK fusions. In CTSB-ALK, $A L K$ is fused with an untranslated exon 1 of $C T S B$, with predicted translation starting in $A L K$ exon 16 or 17, suggesting a novel mechanism of $A L K$ expression in these fusions.

The availability of a large number of tumors with $S T R N-A L K$ or EML4-ALK fusion allowed us to explore for the first time whether different fusion partners are associated with specific phenotypical or clinical tumor characteristics. A potentially interesting finding was that all five PDTC in this study carried STRN-ALK fusions. The number of tumors studied here was still limited and cases of PDTC carrying EML4-ALK have been reported (Landa et al. 2016). Nevertheless, the results of this study raise the possibility that tumors driven by STRN-ALK fusions may have a higher propensity for dedifferentiation. Among PTCs, we observed no differences with respect to phenotypical characteristics of tumors driven by these two main types of $A L K$ fusion.

Clinical behavior of thyroid cancer driven by $A L K$ fusions is not well studied. In our series, two patients who died of disease had PDTC with distant metastases, whereas no mortality was observed among patients with PTC on limited follow-up. ALK-driven PTCs were multifocal in about one-third of the cases and frequently showed infiltrative growth and lymph node metastases. However, when follow-up was available, ten patients with PTC were found to be free of disease. In the literature, 23 patients with $A L K$-translocated thyroid cancer showed no disease recurrence, while distant metastases, persistent disease requiring Crizotinib treatment and deaths of two patients with $A L K$-translocated PDTC have been reported (Table 4 ).

In summary, we confirm the occurrence of $A L K$ fusions in a subset of thyroid cancers, specifically in PTC and PDTC, and demonstrate that STRN and EML4 are the two most common $A L K$ fusion partners, with $\sim 10 \%$ of $A L K$ fusions are to other rare partner genes. The most typical histologic appearance of $A L K$-translocated PTC is that of infiltrative follicular variant or predominant follicular growth with a component of papillary growth. We further demonstrated the utility of $A L K$ fusions in identifying thyroid cancer in cytologically indeterminate FNA samples. The presence of an $A L K$ fusion practically rules out the diagnosis of NIFTP. Aggressive cases of $A L K$ positive thyroid carcinomas are typically PDTC, and the results of this study raise the possibility that tumors driven by STRN-ALK fusions may have a higher predisposition to dedifferentiation (compared to thyroid carcinomas with $E M L 4-A L K$ fusion). Further studies with higher numbers of distinct $A L K$ fusion partners including the novel ones presented here, and more comprehensive clinical follow-up, are needed to determine the clinical behavior of $A L K$-driven thyroid carcinomas.

\section{Supplementary data}

This is linked to the online version of the paper at https://doi.org/10.1530/ ERC-19-0325.

\section{Declaration of interest}

Drs Nikiforov and Nikiforova own IP and receive royalties related to ThyroSeq. Dr Nikiforova has a consultancy agreement with Loxo Oncology.

\section{Funding}

This work was supported in part by the NIH grant R01 CA181150 to Y E $\mathrm{N}$. This project used the University of Pittsburgh Medical Center, Hillman Cancer Center and Tissue and Research Pathology/Pittsburgh Biospecimen Core shared resource which is supported in part by award P30CA047904.

\section{Acknowledgements}

The authors thank Jessica Tebbets for her excellent administrative assistance.

\section{References}

Akagi K, Suzuki T, Stephens RM, Jenkins NA \& Copeland NG 2004 RTCGD: retroviral tagged cancer gene database. Nucleic Acids Research 32 D523-D527. (https://doi.org/10.1093/nar/gkh013)

Arndt A, Steinestel K, Rump A, Sroya M, Bogdanova T, Kovgan L, Port M, Abend M \& Eder S 2018 Anaplastic lymphoma kinase (ALK) gene rearrangements in radiation-related human papillary thyroid carcinoma after the Chernobyl accident. Journal of Pathology. Clinical Research 4 175-183. (https://doi.org/10.1002/cjp2.102)

Bastos AU, De Jesus AC \& Cerutti JM 2018 ETV6-NTRK3 and STRN-ALK kinase fusions are recurrent events in papillary thyroid cancer of adult population. European Journal of Endocrinology 178 83-91. (https://doi.org/10.1530/EJE-17-0499)
C) 2019 Society for Endocrinology Published by Bioscientifica Ltd. Printed in Great Britain 
Cancer Genome Atlas Research Network 2014 Integrated genomic characterization of papillary thyroid carcinoma. Cell 159 676-690. (https://doi.org/10.1016/j.cell.2014.09.050)

Chou A, Fraser S, Toon CW, Clarkson A, Sioson L, Farzin M, Cussigh C, Aniss A, O'neill C, Watson N, et al. 2015 A detailed clinicopathologic study of ALK-translocated papillary thyroid carcinoma. American Journal of Surgical Pathology 39 652-659. (https://doi.org/10.1097/ PAS.0000000000000368)

Cipriani NA, Agarwal S, Dias-Santagata D, Faquin WC \& Sadow PM 2017 Clear cell change in thyroid carcinoma: a clinicopathologic and molecular study with identification of variable genetic anomalies. Thyroid 27 819-824. (https://doi.org/10.1089/ thy.2016.0631)

Demeure MJ, Aziz M, Rosenberg R, Gurley SD, Bussey KJ \& Carpten JD 2014 Whole-genome sequencing of an aggressive BRAF wild-type papillary thyroid cancer identified EML4-ALK translocation as a therapeutic target. World Journal of Surgery 38 1296-1305. (https:// doi.org/10.1007/s00268-014-2485-3)

Durante C, Grani G, Lamartina L, Filetti S, Mandel SJ \& Cooper DS 2018 The diagnosis and management of thyroid nodules: a review. JAMA 319 914-924. (https://doi.org/10.1001/jama.2018.0898)

Efanov AA, Brenner AV, Bogdanova TI, Kelly LM, Liu P, Little MP, Wald AI, Hatch M, Zurnadzy LY, Nikiforova MN, et al. 2018 Investigation of the relationship between radiation dose and gene mutations and fusions in post-Chernobyl thyroid cancer. Journal of the National Cancer Institute 110 371-378. (https://doi.org/10.1093/ jnci/djx209)

Fagin JA \& Wells SA, Jr 2016 Biologic and clinical perspectives on thyroid cancer. New England Journal of Medicine 375 1054-1067. (https://doi.org/10.1056/NEJMra1501993)

Futreal PA, Coin L, Marshall M, Down T, Hubbard T, Wooster R, Rahman N \& Stratton MR 2004 A census of human cancer genes. Nature Reviews. Cancer 4 177-183. (https://doi.org/10.1038/nrc1299)

Gasteiger E, Gattiker A, Hoogland C, Ivanyi I, Appel RD \& Bairoch A 2003 Expasy: the proteomics server for in-depth protein knowledge and analysis. Nucleic Acids Research 31 3784-3788. (https://doi. org/10.1093/nar/gkg563)

Godbert Y, Henriques De Figueiredo B, Bonichon F, Chibon F, Hostein I, Perot G, Dupin C, Daubech A, Belleannee G, Gros A, et al. 2015 Remarkable response to crizotinib in woman with anaplastic lymphoma kinase-rearranged anaplastic thyroid carcinoma. Journal of Clinical Oncology 33 e84-e87. (https://doi.org/10.1200/ JCO.2013.49.6596)

Hamatani K, Mukai M, Takahashi K, Hayashi Y, Nakachi K \& Kusunoki Y 2012 Rearranged anaplastic lymphoma kinase (ALK) gene in adultonset papillary thyroid cancer amongst atomic bomb survivors. Thyroid 22 1153-1159. (https://doi.org/10.1089/thy.2011.0511)

Holla VR, Elamin YY, Bailey AM, Johnson AM, Litzenburger BC, Khotskaya YB, Sanchez NS, Zeng J, Shufean MA, Shaw KR, et al. 2017 ALK: a tyrosine kinase target for cancer therapy. Cold Spring Harbor Molecular Case Studies 3 a001115. (https://doi.org/10.1101/ mcs.a001115)

Huret JL, Ahmad M, Arsaban M, Bernheim A, Cigna J, Desangles F, Guignard JC, Jacquemot-Perbal MC, Labarussias M, Leberre V, et al. 2013 Atlas of genetics and cytogenetics in oncology and haematology in 2013. Nucleic Acids Research 41 D920-D924. (https:// doi.org/10.1093/nar/gks1082)

Iyer MK, Chinnaiyan AM \& Maher CA 2011 ChimeraScan: a tool for identifying chimeric transcription in sequencing data. Bioinformatics 27 2903-2904. (https://doi.org/10.1093/bioinformatics/btr467)

Jeon MJ, Chun SM, Lee JY, Choi KW, Kim D, Kim TY, Jang SJ, Kim WB, Shong YK, Song DE, et al. 2019 Mutational profile of papillary thyroid microcarcinoma with extensive lymph node metastasis. Endocrine 64 130-138. (https://doi.org/10.1007/s12020-019-01842-y)

Ji JH, Oh YL, Hong M, Yun JW, Lee HW, Kim D, Ji Y, Kim DH, Park WY, Shin HT, et al. 2015 Identification of driving ALK fusion genes and genomic landscape of medullary thyroid cancer. PLOS Genetics $\mathbf{1 1}$ e1005467. (https://doi.org/10.1371/journal.pgen.1005467)

Kelly LM, Barila G, Liu P, Evdokimova VN, Trivedi S, Panebianco F, Gandhi M, Carty SE, Hodak SP, Luo J, et al. 2014 Identification of the transforming STRN-ALK fusion as a potential therapeutic target in the aggressive forms of thyroid cancer. PNAS $1114233-4238$. (https://doi.org/10.1073/pnas.1321937111)

Landa I, Ibrahimpasic T, Boucai L, Sinha R, Knauf JA, Shah RH, Dogan S, Ricarte-Filho JC, Krishnamoorthy GP, Xu B, et al. 2016 Genomic and transcriptomic hallmarks of poorly differentiated and anaplastic thyroid cancers. Journal of Clinical Investigation 126 1052-1066. (https://doi.org/10.1172/JCI85271)

Li B \& Dewey CN 2011 RSEM: accurate transcript quantification from RNA-Seq data with or without a reference genome. BMC Bioinformatics 12 323. (https://doi.org/10.1186/1471-2105-12-323)

Li H, Ruan J \& Durbin R 2008 Mapping short DNA sequencing reads and calling variants using mapping quality scores. Genome Research 18 1851-1858. (https://doi.org/10.1101/gr.078212.108)

Liao Y, Smyth GK \& Shi W 2014 featureCounts: an efficient general purpose program for assigning sequence reads to genomic features. Bioinformatics 30 923-930. (https://doi.org/10.1093/bioinformatics/ btt656)

McFadden DG, Dias-Santagata D, Sadow PM, Lynch KD, Lubitz C, Donovan SE, Zheng Z, Le L, Iafrate AJ \& Daniels GH 2014 Identification of oncogenic mutations and gene fusions in the follicular variant of papillary thyroid carcinoma. Journal of Clinical Endocrinology \& Metabolism 99 E2457-E2462. (https://doi. org/10.1210/jc.2014-2611)

Nikiforov YE, Baloch ZW, Hodak SP, Giordano TJ, Lloyd RV, Seethala RR \& Wenig BM 2018 Change in diagnostic criteria for noninvasive follicular thyroid neoplasm with papillary-like nuclear features. JAMA Oncology 4 1125-1126. (https://doi.org/10.1001/ jamaoncol.2018.1446)

Nikiforov YE, Seethala RR, Tallini G, Baloch ZW, Basolo F, Thompson LD, Barletta JA, Wenig BM, Al Ghuzlan A, Kakudo K, et al. 2016 Nomenclature revision for encapsulated follicular variant of papillary thyroid carcinoma: a paradigm shift to reduce overtreatment of indolent tumors. JAMA Oncology 2 1023-1029. (https://doi.org/10.1001/jamaoncol.2016.0386)

Nikiforova MN, Mercurio S, Wald AI, Barbi De Moura M, Callenberg K, Santana-Santos L, Gooding WE, Yip L, Ferris RL \& Nikiforov YE 2018 Analytical performance of the ThyroSeq v3 genomic classifier for cancer diagnosis in thyroid nodules. Cancer 124 1682-1690. (https:// doi.org/10.1002/cncr.31245)

Nikitski AV, Rominski SL, Wankhede M, Kelly LM, Panebianco F, Barila G, Altschuler DL \& Nikiforov YE 2018 Mouse model of poorly differentiated thyroid carcinoma driven by STRN-ALK fusion. American Journal of Pathology 188 2653-2661. (https://doi. org/10.1016/j.ajpath.2018.07.012)

Nikitski AV, Rominski SL, Condello V, Kaya C, Wankhede M, Panebianco F, Yang H, Altschuler DL \& Nikiforov YE 2019 Mouse model of thyroid cancer progression and dedifferentiation driven by STRN-ALK expression and loss of p53: evidence for the existence of two types of poorly differentiated carcinoma. Thyroid [epub]. (https://doi.org/10.1089/thy.2019.0284)

Park G, Kim TH, Lee HO, Lim JA, Won JK, Min HS, Lee KE, Park DJ, Park YJ \& Park WY 2015 Standard immunohistochemistry efficiently screens for anaplastic lymphoma kinase rearrangements in differentiated thyroid cancer. Endocrine-Related Cancer 22 55-63. (https://doi.org/10.1530/ERC-14-0467)

Perot G, Soubeyran I, Ribeiro A, Bonhomme B, Savagner F, BoutetBouzamondo N, Hostein I, Bonichon F, Godbert Y \& Chibon F 2014 Identification of a recurrent STRN/ALK fusion in thyroid carcinomas. PLOS ONE 9 e87170. (https://doi.org/10.1371/journal.pone.0087170)

Pfeifer A, Rusinek D, Żebracka-Gala J, Czarniecka A, Chmielik E, Zembala-Nożyńska E, Wojtaś B, Gielniewski B, Szpak-Ulczok S, Oczko- https://erc.bioscientifica.com

https://doi.org/10.1530/ERC-19-0325 (c) 2019 Society for Endocrinology Published by Bioscientifica Ltd. Printed in Great Britain 
Wojciechowska M, et al. 2019 Novel TG-FGFR1 and TRIM33-NTRK1 transcript fusions in papillary thyroid carcinoma. Genes, Chromosomes \& Cancer 58 558-566. (https://doi.org/10.1002/gcc.22737)

Predescu SA, Predescu DN, Timblin BK, Stan RV \& Malik AB 2003 Intersectin regulates fission and internalization of caveolae in endothelial cells. Molecular Biology of the Cell 14 4997-5010. (https:// doi.org/10.1091/mbc.e03-01-0041)

Rehman AU, Najafi M, Kambouris M, Al-Gazali L, Makrythanasis P, Rad A, Maroofian R, Rajab A, Stark Z, Hunter JV, et al. 2019 Biallelic loss of function variants in PPP1R21 cause a neurodevelopmental syndrome with impaired endocytic function. Human Mutation $\mathbf{4 0}$ 267-280. (https://doi.org/10.1002/humu.23694)

Siegel RL, Miller KD \& Jemal A 2019 Cancer statistics, 2019. CA: A Cancer Journal for Clinicians 69 7-34. (https://doi.org/10.3322/ caac.21551)

Steward DL, Carty SE, Sippel RS, Yang SP, Sosa JA, Sipos JA, Figge JJ, Mandel S, Haugen BR, Burman KD, et al. 2019 Performance of a multigene genomic classifier in thyroid nodules With indeterminate cytology: a prospective blinded multicenter study. JAMA Oncology 5 204-212. (https://doi.org/10.1001/jamaoncol.2018.4616)

Trapnell C, Pachter L \& Salzberg SL 2009 TopHat: discovering splice junctions with RNA-Seq. Bioinformatics 25 1105-1111. (https://doi. org/10.1093/bioinformatics/btp120)

Tsyba L, Nikolaienko O, Dergai O, Dergai M, Novokhatska O, Skrypkina I \& Rynditch A 2011 Intersectin multidomain adaptor proteins: regulation of functional diversity. Gene $\mathbf{4 7 3}$ 67-75. (https:// doi.org/10.1016/j.gene.2010.11.016)

van der Tuin K, Ventayol Garcia M, Corver WE, Khalifa MN, Ruano Neto D, Corssmit EPM, Hes FJ, Links TP, Smit JWA, Plantinga TS, et al. 2019 Targetable gene fusions identified in radioactive iodinerefractory advanced thyroid carcinoma. European Journal of Endocrinology 180 235-241. (https://doi.org/10.1530/EJE-18-0653)

Vanden Borre P, Schrock AB, Anderson PM, Morris JC, 3rd, Heilmann AM, Holmes O, Wang K, Johnson A, Waguespack SG, Ou SI, et al. 2017 Pediatric, adolescent, and young adult thyroid carcinoma harbors frequent and diverse targetable genomic alterations, including kinase fusions. Oncologist 22 255-263. (https:// doi.org/10.1634/theoncologist.2016-0279)

Volante M, Collini P, Nikiforov YE, Sakamoto A, Kakudo K, Katoh R, Lloyd RV, Livolsi VA, Papotti M, Sobrinho-Simoes M, et al. 2007 Poorly differentiated thyroid carcinoma: the Turin proposal for the use of uniform diagnostic criteria and an algorithmic diagnostic approach. American Journal of Surgical Pathology 31 1256-1264. (https://doi.org/10.1097/PAS.0b013e3180309e6a)

Yakirevich E, Resnick MB, Mangray S, Wheeler M, Jackson CL, Lombardo KA, Lee J, Kim KM, Gill AJ, Wang K, et al. 2016 Oncogenic ALK fusion in rare and aggressive subtype of colorectal adenocarcinoma as a potential therapeutic target. Clinical Cancer Research 22 3831-3840. (https://doi.org/10.1158/1078-0432.CCR-153000)

Received in final form 17 September 2019

Accepted 19 September 2019

Accepted Preprint published online 19 September 2019
C) 2019 Society for Endocrinology Published by Bioscientifica Ltd. Printed in Great Britain 